\title{
Fiber Optic Intensity-Modulated Sensors: a Review in Biomechanics
}

\author{
Paulo RORIZ $^{*}$, António RAMOS ${ }^{1}$, José L. SANTOS ${ }^{2}$, and José A. SIMÕES ${ }^{1}$ \\ ${ }^{1}$ Department of Mechanics, University of Aveiro, 3810-193 Aveiro, Portugal \\ ${ }^{2}$ Faculty of Sciences, University of Porto, Rua do Campo Alegre, 687, 4150-179, Porto, Portugal \\ *Corresponding author: Paulo RORIZ_Ｅ-mail: paulororiz@ua.pt
}

\begin{abstract}
Fiber optic sensors have a set of properties that make them very attractive in biomechanics. However, they remain unknown to many who work in the field. Some possible causes are scarce information, few research groups using them in a routine basis, and even fewer companies offering turnkey and affordable solutions. Nevertheless, as optical fibers revolutionize the way of carrying data in telecommunications, a similar trend is detectable in the world of sensing. The present review aims to describe the most relevant contributions of fiber sensing in biomechanics since their introduction, from 1960s to the present, focusing on intensity-based configurations. An effort has been made to identify key researchers, research and development (R\&D) groups and main applications.
\end{abstract}

Keywords: Biomechanics, fiber optic sensors, intensity-modulated sensors

Citation: Paulo RORIZ, António RAMOS, José L. SANTOS, and José A. SIMÕES, "Fiber Optic Intensity-Modulated Sensors: a Review in Biomechanics," Photonic Sensors, DOI: 10.1007/s13320-012-0090-3.

\section{Introduction}

Biomechanics is the mechanics applied to living bodies with special emphasis given to the human body. It is a field of a confluence of several disciplines from engineering, medicine and sports, such as mechanics, anatomy, physiology, orthopaedics, rehabilitation, ergonomics, kinesiology, motor control and many others.

A major topic is movement analysis. It helps to assess the body's kinematics and dynamics, either to optimize an athlete's skill and his performance, either to assess gait patterns and postures of injured subjects. Some good examples of the optical technology applied to this topic are: (1) 3D motion capture systems using the advanced digital optical technology [1-4]; (2) pedobarographs or optical pressure platforms [5-8]; (3) fiber optic goniometers $[9,10]$.

Clinical biomechanics is also an important topic. Among a wide variety of applications, it includes the design of orthopaedic devices, such as prosthesis and implants. Thus, the issues of materials biocompatibility, their physical and mechanical properties, along with finite element analysis and mechanical tests to optimize the design and predict the devices performance, their durability and efficacy, are frequently reported. Consequently, in-vitro, ex-vivo and in-vivo studies are regular in biomechanics. More recently, interesting topics including tissue, cell and molecular biomechanics have been introduced. A good example of the optical technology applied to this topic is near infrared (NIR) spectroscopy (NIRS), allowing to assess the

Received: 1 August 2012 / Revised version: 16 August 2012

(C) The Author(s) 2012. This article is published with open access at Springerlink.com 
optical properties of cartilage and evaluate low-grade lesions [11-14]. The clinical biomechanics also poses interesting challenges in developing sensors for minimally invasive procedures, capable of not disturbing the natural biomechanics of body structures, mainly if in-vivo applications are pursued. That is why optical fibers sensors hold enormous potential for the use in the biomechanics. Due to the biocompatibility of the high-purity fused silica glass $\left(\mathrm{SiO}_{2}\right)$, an optical fiber has the potential to neither adversely affect the physiological environment, nor be adversely affected by it [15]. Other important attributes that will be discussed in this paper include small size, light weight, geometrical flexibility, chemical inertness, electric and thermal insulation, and immunity to electromagnetic interference [16-19].

An optical fiber guides light making possible to illuminate and capture images from the inside of the body. Indeed, the initial optical fiber based systems were proposed for endoscopic procedures, still before the 1960s [20]. It was, however, the possibility of using an optical fiber to carry information that revolutionized the world of communication. Furthermore, an optical fiber allows to relate a change in radiation properties (intensity, optical frequency, phase and polarization) with a change in a physical quantity (e.g., strain and pressure), and this possibility is also introducing substantial changes in the world of sensing.

The initial fiber optic sensors were proposed during the 1960s, based on intensity-modulated configurations. Since that time, a myriad of solutions have been presented covering many configurations and applications. However, the vast majority have been used for research and investigational purposes. With some exceptions, few have presented turnkey solutions, and fewer have reached commercialization. Table 1 is a list of companies offering fiber optic sensing solutions for the biomechanics and other related applications. Nevertheless, these companies and fiber optic sensors remain unknown to many engineers, biomechanists, clinicians and researchers. Most likely, this is related to the fact that their education and practice are focused on conventional sensors and non-optical technologies.

Table 1 Companies in the market offering fiber optic sensors suitable for biomechanics applications.

\begin{tabular}{lll}
\hline \multicolumn{1}{c}{ Company } & \multicolumn{1}{c}{ Local, country } & \multicolumn{1}{c}{ Website } \\
\hline 5DT Inc. & Irvine, CA, USA & $\underline{\text { www.5dt.com }}$ \\
ADInstruments, Inc. & Colorado Springs, CO, USA & $\underline{\text { www.adinstruments.com }}$ \\
Arrow International, Inc (Teleflex Medical) & Research Triangle Park, NC, USA & $\underline{\text { www.arrowintl.com }}$ \\
BioTechPlex & Escondido, CA, USA & $\underline{\text { www.biotechplex.com }}$ \\
Camino Laboratories (Integra LifeSciences) & Plainsboro, NJ, USA & $\underline{\text { www.integralife.com }}$ \\
Delsys Inc. & Boston, MA, USA & $\underline{\text { www.delsys.com }}$ \\
Endosense, SA & Geneva, Switzerland & $\underline{\text { www.endosense.com }}$ \\
FISO Technologies & Québec, Canada & $\underline{\text { www.fiso.com }}$ \\
InnerSpace Medical, Inc. & Tustin, CA, USA & $\underline{\text { www.innerspacemedical.com }}$ \\
InvivoSense & Trondheim, Norway; & $\underline{\text { www.invivosense.co.uk }}$ \\
LumaSense Technologies & Santa Clara, CA, USA & $\underline{\text { www.lumasenseinc.com }}$ \\
Luna Innovations & Blacksburg, VA, USA & $\underline{\text { www.lunainnovations.com }}$ \\
MAQUET Getinge Group & Rastatt, Germany & $\underline{\text { http://ca.maquet.com }}$ \\
Measurand Inc. & New Brunswick, Canada & $\underline{\text { www.measurand.com }}$ \\
Neoptix Inc. & Québec, Canada & $\underline{\text { www.neoptix.com }}$ \\
Opsens & Québec, Canada & $\underline{\text { www.opsens.com }}$ \\
Radi Medical Systems (St. Jude Medical Systems AB) & Uppsala, Sweden & $\underline{\text { www.radi.se }}$ \\
RJC Enterprises, LLC & Bothell, WA, USA & $\underline{\text { www.ricenterprises.net }}$ \\
Samba Sensors & Västra Frölunda, Sweden & $\underline{\text { www.sambasensors.com }}$ \\
\hline
\end{tabular}


The present review aims to identify the most relevant contributions in biomechanics oriented fiber optic sensing, pointing out applications, researchers and research and development (R\&D) groups that have been working in the field and related areas.

\section{Sensor classification}

Fiber optic sensors can be classified accordingly to their working principles into some major categories. One of them relies on the modulation by the measurand of the light intensity, identified as intensity-modulated configurations, the first to be reported in the literature. Nowadays, they stand for a mature solution in many applications and are relatively simple to interrogate [19]. Sensing devices based on fiber Bragg gratings and Fabry-Pérot structures are also of great interests and have already been applied in the biomechanics. Compared to intensity-modulated schemes, they stand for higher sensitivity and resolution, but at the expense of relatively complex interrogation/detection techniques [21]. Our approach has been focused on intensity-modulated configurations, but all of them should be addressed if the full spectrum of biomechanics applications has to be known.

Most common configurations of intensity-modulated sensors applied in biomechanics are:

(1) An optical fiber with its tip placed in front of a movable reflecting membrane/mirror. The optical fiber guides the light of the source to the fiber tip, and under the influence of the measurand, the original membrane distance to the fiber tip changes, as well as the intensity of the reflected light that is coupled by the same fiber or another fiber parallel to the first one (Fig. 1). As it will be seen, first studies made use of similar configurations. However, instead of a single optical fiber, bundles of optical fibers have been used as waveguides.

(2) An optical fiber submitted to bending or curvature. These actions will result in light loss into the cladding and lead to a decrease in the light intensity (Fig. 2).

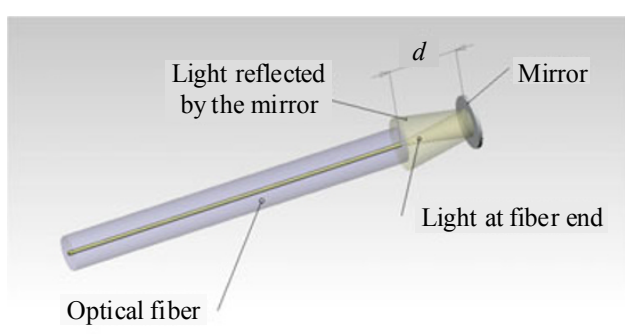

Fig. 1 An optical fiber placed in front of a movable reflecting membrane/mirror: the back-reflected intensity decreases when the distance, $d$, increases.

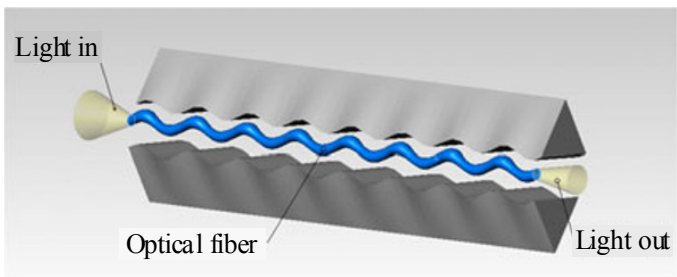

Fig. 2 Light losses due to microbending.

\section{Earlier intensity-modulated configurations}

The initial papers reporting fiber optic sensors were published in the early 1960s. They were based on intensity-modulated schemes and initially proposed for the intravascular and cardiac applications. In 1960, Michael Polanyi (American Optical Company, Southbridge, MA) and Robert Hehir (St. Vicent Hospital, Worcester, MA) presented an optical system for measurement of the in-vivo oxygen saturation and dye concentration in the blood [22] (Fig. 3).

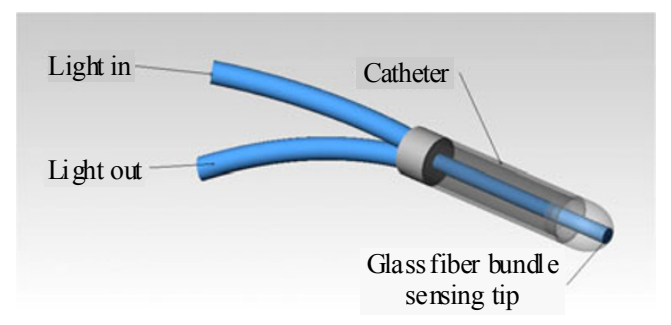

Fig. 3 Schematic drawing of the Polanyi sensor (adapted from[23]).

The innovative contribution of the system was its sensing probe, made of two glass fibers bundles located within a catheter (about 150 fibers with about $50 \mu \mathrm{m}$ in diameter each) [22-24]. These two bundles have been used as waveguides, one to guide the filtered light from a tungsten lamp source to the 
tip of the catheter, the other to guide the back-scattered and diffusely reflected light, modified in its spectral distribution due to blood interaction, into a photocell. The pulses of the source were located at $805 \mu \mathrm{m}$ and $660 \mu \mathrm{m}$, to measure the oxygen saturation, and at $900 \mu \mathrm{m}$ and $805 \mu \mathrm{m}$, to measure the dye concentration [23]. The reflected light has been analyzed spectrophotometrically, on the basis of the linear relationship between the measurand and the ratio of the intensities of the two reflected wavelengths [25]. The following years have been particularly prolific using this or similar techniques in the laboratory and clinical environments [26-35].

It was also in the 1960 s that fiber optic sensors became interesting for pressure measurement [36-39]. They intended to solve the drawbacks of standard fluid-filled catheters [40], such as hydrostatic artifacts caused by body movements and the necessity of flushing them to maintain accuracy [41]. The working principle of these new sensors also is based on the variation of the light intensity. To sense pressure, the light from the source is guided to a movable membrane which, under pressure, reflects the light back to a photodetector $[36,37]$. Several US patents were presented at that time [42-44]. Among all contributions, the work of Lekholm and Lindström at the Research Laboratory of Electronics of the Chalmers University of Technology (Gothenburg, Sweden) deserves to be highlighted. Authors have presented a sensor for in-vivo blood pressure measurement [37, 39] (Fig. 4).

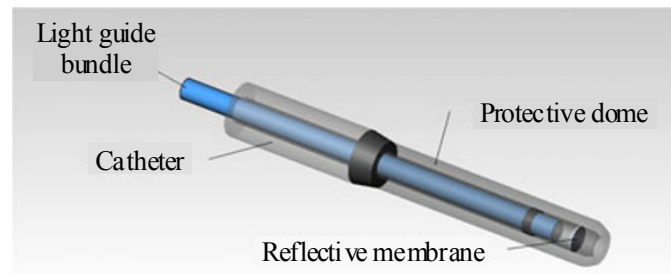

Fig. 4 Schematic drawing of the Lekholm and Lindströn sensor (adapted from [39]).

The above sensor was extensively described, covering the theoretical topics of fiber optics properties, membrane reflection, operation modes, number of fibers and their distribution, membrane mechanics, volume displacement, frequency dependence and limitations [39]. Error sources, sensitivity and miniaturization, failure and redundancy were also addressed [39].

One of the innovative features of the sensor was its miniaturization, evidencing sensor heads of only 0.85-mm (unshielded) and 1.5-m diameters. These heads consisted of air-filled chambers covered by a $6-\mu \mathrm{m}$ pressure sensitive membrane of beryllium-copper. As in previous works, the guiding system was made of two independent optical fiber bundles, one to guide the light, from a gallium-arsenide light emitting diode (LED) source to the sensor head [later versions included a microminiature glow lamp powered by the direct current (DC)], the other to guide the reflected light into a photodetector. Near the reflective membrane, the optical fibers were randomly distributed allowing for higher miniaturization of the sensor head [39]. Another interesting feature of the sensor was its insensitivity to mechanical vibrations, shocks, and movements due to a light and stiff membrane. The cross sensitivity to temperature has been observed. Nevertheless, under temperature variations from $20{ }^{\circ} \mathrm{C}$ to $37{ }^{\circ} \mathrm{C}$, zero drift was reported after about 40s [39]. The initial fabricated probes had a flat frequency response from static pressure to $200 \mathrm{~Hz}$ [37], increasing to $15 \mathrm{kHz}$ in the following experiments [39]. After successful tests on one dog and one man [37], clinical tests have followed [39].

Similar intensity-modulated sensors with their membranes located at the tip of the sensor have since been reported for intravascular and intracardiac pressure measurement [45, 46]. Nevertheless, sensors with membranes located at the tip of the probe could lead to erroneous intravascular readings due to tip collisions with the blood vessels or the ventricular walls (the so-called wall or piston 
effect) and promote clot formation for long periods of monitoring [47, 48]. These drawbacks could be reduced by changing the location of the sensing membranes to the sides of the probe. Taylor et al. in 1972 [47] and Matsumoto et al. [48] in 1978, implemented this feature in fiber optic sensors, intended to monitor multiple physiologic changes, such as the cardiac output, oxygen saturation, dye clearance, intravascular pressure, and heart rhythm (Fig. 5). Nevertheless, tip and side-hole configurations have been adopted up to today. In fact, the most important achievement in the following years was miniaturization of sensor probes using microfabrication techniques [49-53].

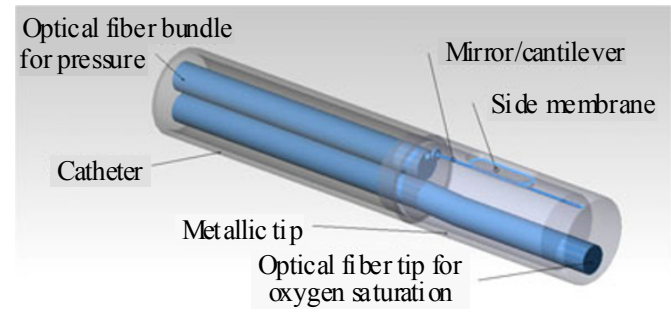

Fig. 5 Schematic drawing of the Matsumoto sensor, intended for pressure and oxygen saturation measurement, adapted from [48] (a side membrane has been used for pressure measurement and a tip configuration for oxygen saturation).

Besides intravascular pressure measurement, similar intensity-modulated configurations to the one proposed by Lekholm and Lindström [37, 39] have been explored to measure pressure in other sites of the human body. For example, in the 1970s, Epstein et al. [54] and Wald et al. [55, 56], both from the Department of Neurosurgery and Neurology of the New York University Medical Center, were the first to apply optical fibers to measure the intracranial pressure (ICP). Vidyasagar et al. [57, 58] adapted the technique for non-invasive purposes through the measurement of the anterior fontanel pressure in newborns. Authors stated the advantage of electric insulation provided by optical fibers to eliminate the risk of electric shocks. The system they have used was probably the first to be commercially available (Ladd Intracranial pressure monitoring device, Model 1700, Ladd Research, Williston, VT). However, while a significant correlation between the anterior fontanel pressure and ICP was reported, the same was not observed by others [59]. It seems the extradurally technique has the disadvantage of signal damping and a tendency to read higher than the true ICP [60].

\section{Earlier commercial solutions}

The configuration proposed by Lekholm and Lindström [37, 39] was also the basis for the development of Camino pressure sensors, probably the most widespread dual-beam referencing intensity-modulated based sensors (Camino Laboratories, San Diego, CA, USA; acquired by Integra LifeSciences; Plainsboro, NJ, USA) [61]. In 1996, Keck reported the company had been producing around 60000 devices/year [62]. This transducer-tipped catheter consisted of a tip enclosed in a saline-filled sheath with side holes (Fig. 6). A pressure sensitive diaphragm varied its distance to the optical fibers changing the intensity of the reflected light.

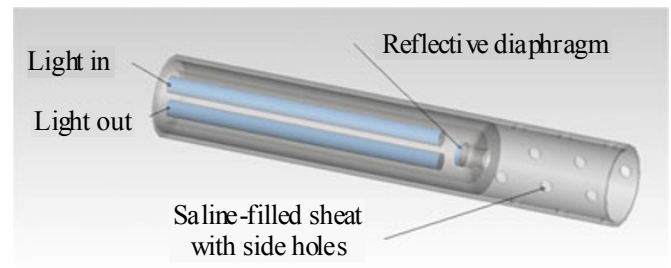

Fig. 6 Schematic drawing of earlier Camino sensors (adapted from [63]).

Following the above original contributions, Camino sensors became popular in the 1980s, and since that time they have been extensively used for pressure measurement in different sites of the body, as in the brain, muscles and joints.

In the late 1980s, Crenshaw et al. [63], from the Division of Orthopaedics and Rehabilitation of the University of California (San Diego, CA, USA) and the NASA-Ames Research Center (Moffett Field, California, USA), were the first to apply Camino sensors (model 110-D) to measure intramuscular 
pressure (IMP), either in animals or in human volunteers. These sensors proved to be insensitive to hydrostatic artifacts caused by body movements and capable of long-term measurement $(\approx 2.5 \mathrm{~h})$ without flushing them to maintain accuracy [63]. Conversely, long-term measurement was also associated with patient discomfort, probably due to the size and rigidity of the polyethylene sheath enclosing the sensor. Even so, these IMP sensors were used in many biomechanics applications, such as during isometric and concentric exercises [64]; to demonstrate that IMP varied with the muscle depth [65]; to study compartment syndrome following prolonged pelvic surgery [66]; and to analyze muscles contribution during gait [67].

Pedowitz et al. [68], also from the Division of Orthopaedics and Rehabilitation of the University of California, applied Camino sensors to measure intraarticular pressure (IAP), namely during continuous passive motion of the knee joint, a common post-surgery therapeutic procedure. In the following years, IAP was also monitored in cadaveric glenohumeral joints to study its relation with the range of movement of the shoulder joint [69]; during typing tasks to measure cubital tunnel pressures [70]; and in patients suffering from cubital tunnel syndrome [71, 72].

It was, however, for ICP measurement that Camino sensors became popular, namely the model 110-4B. They were considered to be accurate and reliable for ICP monitoring, evidencing high-quality readings under laboratory and clinical conditions, a good correlation with strain gauge sensors and fluid-filled systems, insensitivity to hydrostatic artifacts and no flushing or infusion requirements [73-78]. On the other hand, they also underwent extensive scrutiny leading to identification of several drawbacks and questioning their routine use, particularly in clinical practice. Reported drawbacks included sensor failure (e.g., breakage, cable kinking, probe dislocation, abnormal readings), contamination, infection, hemorrhage, drift, and magnetic resonance imaging (MRI) incompatibility due to the presence of ferromagnetic components $[74,76-88]$.

Alternative sensors were proposed, particularly using Fabry-Pérot configurations [41, 89, 90], but their description is away from the scope of the present review.

Meanwhile, a good example of novel applications of light intensity-modulated sensors supported by reflective membranes is the radiofrequency $(\mathrm{RF})$ ablation catheter with force feedback, presented by Polygerinos et al. [91, 92], from the Department of Mechanical Engineering of King's College of London. Three plastic optical fibers were aligned inside a plastic catheter in a circular pattern to provide a three axes force sensing system (Fig. 7). The sensor was tested in an artificial blood artery showing a working range of 0 to $1.1 \mathrm{~N}$, a resolution of $0.04 \mathrm{~N}$ and good dynamic response.

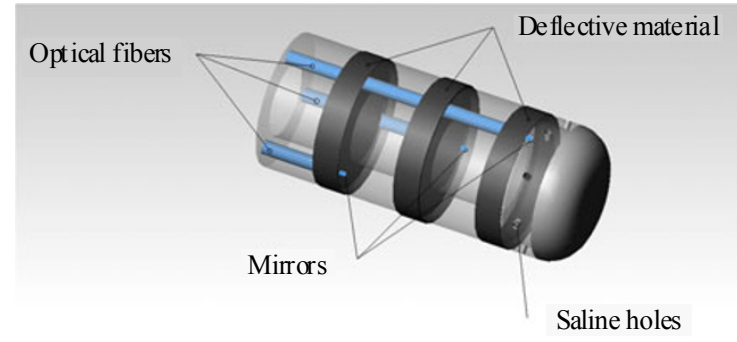

Fig. 7 Schematic drawing of the Polygerinos sensor (adapted from $[91,92])$.

\section{Intensity-modulated sensors based on bending}

Intensity-modulated schemes based on macro- or micro-bending were proposed for biomechanical applications. As for almost intensity-based sensors, they were easy to fabricate and require simple interrogations techniques if fine precision was not required [93-95]. One of the first applications in biomechanics was in dentistry. In 1995, Kopola et al. [96], from the University of Oulu (Finland), proposed a device to measure human biting forces consisting of a mouthpiece, made of two stainless steel plates, and a microbending fiber optic sensor 
placed between them. The sensor was able to measure forces ranging from 0 to $1000 \mathrm{~N}$ with a resolution of $10 \mathrm{~N}$ [96].

Also in the 1990s, another group from Finland, led by Paavo Komi, at the Biology of Physical Activity Department of the University of Jyväskylä, in collaboration with researchers from the Laboratoire de Physiologie, GIP Exercise (Lyon, France), made important contributions in the study of tendons and ligaments biomechanics. They explored fiber optic sensors as an attempt to reduce the errors introduced by large conventional buckle transducers and minimize the subject's complaints [97]. In their first study, a needle was used to guide a $500-\mu \mathrm{m}$-diameter optical fiber into the rabbit common calcaneal tendon [97]. The fiber had a polymethol metachrylate core and a fluorinated polymer cladding. After removal of the needle, the tensile loads applied to the tendon were able to bend the optical fiber leading to changes in light intensity. The fiber was illuminated by an infrared LED, with the central wavelength at $820 \mathrm{~nm}$, and the detector was an integrated circuit photodiode. To assess tendon forces, the system was calibrated using static equilibrium conditions. Hysteresis was negligible, and despite a slight time delay for the optical sensor response, a good agreement with a reference strain gauge transducer was obtained [97]. In-vivo studies followed their first ex-vivo experiment. The majority of them resulted from cooperation between the University of Jyväskylä and other institutions, such as the Institute for Biomechanics of the German Sport University of Cologne (Cologne, Germany) [98-100]. These studies reported the Achilles tendon force contribution during locomotion [101, 102]; individual muscle contributions to the Achilles tendon force [98]; leg muscles contributions to perform standardized jumps [103]; the muscle behavior during jump skills [99]; and the interaction between lower leg muscles and the Achilles tendon in walking [100].

Compared to buckle transducers, a clear advantage of these sensors is their minimally invasive impact since there are smaller and only require an anesthetic cream, applied to the skin surrounding the tendon, instead of anlar anesthesia [102]. However, the validity of previous studies has been questioned. Contradicting the original findings by Komi et al. [97], a nonlinear relationship was observed between the sensor output and the tendon force, requiring the use of third order polynomials for adequate fitting [104]. Hysteresis [104, 105], cable migration $[104,106]$, loading rate $[105,106]$, tendon creep [107], calibration procedures [108] and skin movement artifacts [106] were also pointed as possible sources of error in force prediction. To diminish these sources of error is a challenge because soft tissues are complex structures with nonlinear, visco or poroelastic properties requiring the most accurate sensors and techniques to obtain precise measurements.

The macrobending losses of an optical fiber have also been explored to monitor respiratory and cardiac functions, namely through the fiber optic respiratory plethysmography (FORP) technique. This non-invasive technique was firstly described by Augousti et al. in 1993 [109], at the School of Life Sciences of the Kingston University (United Kingdom) and was based on a notional geometrical model of the human respiratory system that consisted of two stacked connected cylinders, with the top cylinder representing the thorax and the lower abdomen [110]. It was presented as an alternative to the respiratory inductive plethysmograph technique, considered to be expensive and susceptible to electromagnetic interference [109, 111]. Authors also presented a improved version based on a novel figure-of-eight loop configuration, contributing for the increased linearity of response, less mechanical resistance and hysteresis [112]. The FORP technique was also explored by others [113-115]. Such an example was the FORP system presented by Davis et al. [113], from the Centre for Imaging and Advanced Optics 
of the School of Biophysical Sciences and Electrical Engineering (Swinburne University of Technology, Melbourne, Australia). The system was improved to monitor children high-frequency, low amplitude chest wall movements, claiming for no risk of electric noise and shock [114].

The possibility to apply optical fibers into textiles and create smart wearable clothes to monitor vital functions and motion was an important application in biomechanics.

Initial contributions were focused on gloves to assess the hand/fingers motion and interact with virtual environments. A large variety of sensors have been employed, including strain gauges, bend sensors, fiber optics, pneumatics, Hall effect sensors, among others [116-119]. Actually, initial gloves prototypes, such as the Sayre glove, developed in 1977 by Thomas de Fanti and Daniel Sandin (University of Illinois, Chicago, IL, USA), were based on light attenuation caused by bend of a flexible tube (not an optical fiber), with a light source at one end and a photocell at the other [116]. However, it was commercialization of DataGlove ${ }^{\mathrm{TM}}$ that triggered research about these devices and spread their popularity worldwide [119]. DataGlove $^{\mathrm{TM}}$ was developed by Zimmerman et al. [120] at VPL Research (VPL Research, Inc.; acquired by SunMicrosystems which was acquired by Oracle Corporation, Redwood Shores, CA, USA), the first company to sell virtual reality gloves and the pioneer in 3D computer graphics. It consisted of a hand to machine the interface device providing real-time motion of the hand. A neoprene glove incorporating several sensors and technologies was used. The optical part of it consisted of patented optical goniometers intended to measure the fingers joints motion [121]. These devices were made of a flexible black rubber tube with a reflective inner wall coated with aluminum spray (a possible embodiment). An optical source and a photosensitive detector (it could be an optical fiber), were placed at the ends of the tube allowed for measurement of light attenuation concomitant with the bend of the tube. Wise et al. [122], from the Rehabilitation Research and Development Center of VA Medical Center (Palo Alto, CA, USA), evaluated DataGloveTM performance for clinical application. Inclusion of abduction/adduction measurement, as well as the wrist motion and full characterization of the thumb movement, has been recommended to be used as an effective clinical tool [122].

Fifth Dimension Technologies (5DT, Irvine, CA) developed another glove using optical fibers to sense the fingers motion. The sensor was modulated by the intensity to sense the fingers angular motion with a 5- (one joint per finger) or 14-sensor arrangement (two joints per finger) [123, 124]. It has been used as the primary manual input device for virtual reality technologies [123] and to improve hand function in adolescents with cerebral palsy, by means of the in-home gaming technology [124, 125]. It was, however, an expensive device (the current lower price for one glove is US\$995) [126]. The price increased in versions incorporating further sensors or intended for specific applications, such as for the MRI environment. In fact, other affordable sensors were presented, such as the non-optical bend sensor (Flexpoint, South Draper, UT) developed by Simone et al. [117] for 24-hour daily life monitoring of finger motion. The sensor total cost was less than US\$40 [117].

Miniature fiber optic goniometers seemed also interesting to study the association between highly repetitive movement and musculoskeletal disorder. The impact of typing was a possible application, which was studied by Nelson et al. [9] (General Motors, Orion Assembly Center, MI, USA), using opto-electric finger goniometers, developed in the Biodynamics Laboratory of the Ohio State University (Columbus, OH, USA). A similar study, using commercial sensors (Shape Sensors, Measurand Inc., New Brunswick, Canada), was performed by Jindrich et al. [10] at the Department of Environmental Health of the Harvard School of 
Public Health (Boston, MA, USA).

The current research has been focused on the process of embedding fiber optic sensors into textile. In 2006, the OFSETH European project (Optical Fiber Sensors Embedded into technical Textile for Healthcare - OFSETH), a $€ 3.5$ million project made its contribution in the field [127, 128]. Several configurations, such as intensity-modulated, fiber Bragg gratings and optical time domain reflectometry (OTDR), were explored for healthcare applications. Project results were published for respiratory monitoring in the MRI environment [129-132] and pulse oximetry using near infrared spectrometry [133].

To conclude our approach to intensity-modulated sensors, a reference to pressure mapping devices seems mandatory. Several companies such as Tekscan Inc. (South Boston, MA, USA) and Novel $\mathrm{GmbH}$ (Munich, Germany) already offered powerful accurate electronic based systems at the relatively low cost for many biomechanical applications. Thus, optical fiber based systems should be capable of competing with these standard technologies. Meanwhile, some of their limitations were described. Tekscan sensors were based on conductive elastomers, which might exhibit nonlinear response, hysteresis, and gradual voltage drift [134]. The novel sensors used capacitive-based transducers, which could be affected by electrical interference and suffered from low spatial resolution, drift, and high sensitivity to temperature [134]. Moreover, with both technologies only normal loads and pressures could be measured. Until now, few alternative contributions have been presented in this field. The work of Wang et al. [135], from the Departments of Mechanical Engineering and Orthopaedics and Sports Medicine of the University of Washington (Seattle, WA, USA), is of particular interest because it represents the first contribution in the field using a bend loss technique. A $2 \times 2$ array of multimode fibers, embedded into the high-compliance material and forming four orthogonal intersection points, was developed to form the basic sensing sheet. Under compressive loading, light attenuation caused by physical deformation of the fibers at the intersection points allowed to calculate the $(x, y)$ coordinates of the pressure point and the corresponding normal stress. To obtain shear stress, two layers of the basic sensing sheet, placed between gel/polymeric shoe insole pads, were used. In this way, the relative difference between the corresponding pressure points allowed calculation of the amount of shear. Repeatable results were obtained under bench mechanical loading tests. The minimum detectable vertical and shear forces were $0.4 \mathrm{~N}$ and $2.2 \mathrm{~N}$ (at $60^{\circ}$ pitch angle), respectively. To address some limitations of the previous configuration (e.g., low spatial resolution, consistent and accurate manufacturing of the sensor, cost and noise), a batch process to fabricate Poly (dimethylsiloxane) (PDMS) as the optical medium, and a neural network technique to provide an accurate description of the force distribution were proposed [134, 136, 137]. After successful bench tests, the same group recently presented a full-scale foot pressure/shear sensor, capable of measuring normal forces ranging from $19.09 \mathrm{kPa}$ to $1000 \mathrm{kPa}$ [138].

\section{Final remarks}

Intensity modulated fiber optic sensors applied for biomechanics have been reviewed. Usually, they fall into one of two categories: a reflective membrane/mirror that changes its distance to the fiber tip; or an optical fiber that bends accordingly to the action of the measurand. While the first configuration has been used to sense pressure in many sites of the human body, the second seems to offer a wide range of applications from tendons force measurement to respiratory monitoring and goniometric applications.

Since the middle 1960s, the fiber optic technology has progressed at an astonishing rate, triggered by the increasingly demands of large 
capacity communication networks, turning out the optical fiber systems to be nowadays the backbone of the information society. This movement benefits the development of other applications of the optical fiber, most notably in the sensing domain where the intrinsic characteristics of the fiber remarkably match the ideal requirements of a sensor system. Indeed, besides the fiber being the sensing element and the communication (telemetry) channel, it brings the optical field (optical power) to the measurement region, eliminating the need of additional wiring for power delivery to the sensor, a need in many sensing approaches as is the case of electrical sensing in most of its applications. Therefore, the fast development of this sensing technology and its utilization in a diversity of areas are not surprising, as is the case of biomechanics. Here, what has been achieved so far, reviewed in this paper when considering measurand induced optical power modulation, is a clear indication of how valuable the fiber sensing approach is when addressing this field and provides an insight into what can be achieved in the future.

\section{Acknowledgment}

This work was supported by the Portuguese Foundation for Science and Technology (FCT) fellowship SFRH/BD/45130/2008.

Authors would like to thank Orlando Frazão, from INESC Porto, by his constant support and encouragement.

Open Access This article is distributed under the terms of the Creative Commons Attribution License which permits any use, distribution, and reproduction in any medium, provided the original author(s) and source are credited.

\section{References}

[1] A. Lees, J. Vanrenterghem, and D. D. Clercq,
"Understanding how an arm swing enhances performance in the vertical jump," Journal of Biomechanics, vol. 37, no. 12, pp. 1929-1940, 2004.

[2] N. Sakai and S. Shimawaki, "Hand motion analysis during touch-typing using VICON system with finger force plate," Journal of Biomechanics, vol. 39, sup. 1, pp. S166, 2006.

[3] H. Liu, C. Holt, and S. Evans, "Accuracy and repeatability of an optical motion analysis system for measuring small deformations of biological tissues," Journal of Biomechanics, vol. 40, no. 1, pp. 210-214, 2007.

[4] M. Windolf, H., Germany, and M. Morlock, "Systematic accuracy and precision analysis of video motion capturing systems - exemplified on the Vicon-460 system," Journal of Biomechanics, vol. 41, no. 12, pp. 2776-2780, 2008.

[5] R. P. Betts, T. Duckworth, I. G. Austin, S. P. Crocker, and S. Moore, "Critical light reflection at a plastic/glass interface and its application to foot pressure measurements," Journal of Medical Engineering and Technology, vol. 4, no. 3, pp. 136-142, 1980.

[6] C. I. Franks, R. P. Betts, and T. Duckworth, "Microprocessor-based image processing system for dynamic foot pressure studies," Medical and Biological Engineering and Computing, vol. 21, no. 5, pp. 566-572, 1983.

[7] C. I. Franks and R. P. Betts, "Selection of transducer material for use with 'optical' foot pressure systems," Journal of Biomedical Engineering, vol. 10, no. 4, pp. 365-367, 1988.

[8] A. Gefen, "The in vivo elastic properties of the plantar fascia during the contact phase of walking," Foot and Ankle International, vol. 24, no. 3, pp. 238-244, 2003.

[9] J. E. Nelson, D. E. Treaster, and W. S. Marras, "Finger motion, wrist motion and tendon travel as a function of keyboard angles," Clinical Biomechanics, vol. 15, no. 7, pp. 489-498, 2000.

[10]D. L. Jindrich, A. D. Balakrishnan, and J. T. Dennerlein, "Finger joint impedance during tapping on a computer keyswitch," Journal of Biomechanics, vol. 37, no. 10, pp. 1589-1596, 2004.

[11] G. Spahn, H. Plettenberg, E. Kahl, Klinger, M. Hans, T. M. Kockley, and G. O. Hofmann, "Near-infrared (NIR) spectroscopy. a new method for arthroscopic evaluation of low grade degenerated cartilage lesions. results of a pilot study," BMC Musculoskeletal Disorders, vol. 8, no. 1, pp. 47, 2007.

[12] G. O. Hofmann, J. Marticke, R. Grossstück, M. Hoffmann, M. Lange, H. K. Plettenberg, et al., 
"Detection and evaluation of initial cartilage pathology in man: a comparison between MRT, arthroscopy and near-infrared spectroscopy (NIR) in their relation to initial knee pain," Pathophysiology, vol. 17, no. 1, pp. 1-8, 2010.

[13] G. Spahn, H. M. Klinger, M. Baums, M. Hoffmann, H. Plettenberg, A. Kroker, et al., "Near-infrared spectroscopy for arthroscopic evaluation of cartilage lesions: results of a blinded, prospective, interobserver study," The American Journal of Sports Medicine, vol. 38, no. 12, pp. 2516-2521, 2010.

[14] J. K. Marticke, A. Hösselbarth, K. L. Hoffmeier, I .Marintschev, S. Otto, M. Lange, H. K. Plettenberg, et al., "How do visual, spectroscopic and biomechanical changes of cartilage correlate in osteoarthritic knee joints," Clinical Biomechanics, vol. 25, no. 4, pp. 332-340, 2010.

[15] M. Thompson and E. T. Vandenberg, "In vivo probes: problems and perspectives," Clinical Biochemistry, vol. 19, no. 5, pp. 255-261, 1986.

[16] J. Peterson and G. Vurek, "Fiber-optic sensors for biomedical applications," Science, vol. 224, no. 4645, pp. 123-127, 1984.

[17] D. A. Jackson and J. D. C. Jones, "Fiber optic sensors," Optica Acta: International Journal of Optics, vol. 33, no. 12, pp. 1469-1503, 1986.

[18] E. Udd, Fiber optic sensors: an introduction for engineers and scientists. New York: John Wiley \& Sons Inc., 1991, pp. 496.

[19] E. Udd, "An overview of fiber-optic sensors," Review of Scientific Instruments, vol. 66, no. 8, pp. 4015-4030, 1995.

[20] H. H. Hopkins and N. S. Kapany, "A flexible fiberscope, using static scanning," Nature, vol. 173, pp. 39-41, 1954.

[21] F. T. S. Yu and Y. Shizhuo, Fiber optic sensors, New York: Marcel Dekker Inc., 2002, pp. 509.

[22] M. L. Polanyi and R. M. Hehir, "New reflection oximeter," Review of Scientific Instruments, vol. 31, no. 4, pp. 401-403, 1960.

[23] M. L. Polanyi and R. M. Hehir, "In vivo oximeter with fast dynamic response," Review of Scientific Instruments, vol. 33, no. 10, pp. 1050-1054, 1962.

[24] P. F. Ware, M. L. Polanyi, R. M. Hehir, J. F. Stapleton, J. I. Sanders, and S. L. Kocot, "A new reflection oximeter," The Journal of Thoracic and Cardiovascular Surgery, vol. 42, pp. 580-588, 1961.

[25] L. C. Clark, R. Wolf, D. Grager, and Z. Taylor, "Continuous recording of blood oxygen tensions by polarography," Journal of Applied Physiology, vol. 6, no. 3, pp. 189-193, 1953.
[26] Y. Enson, W. A. Briscoe, M. L. Polanyi, and A. Cournand, "In vivo studies with an intravascular and intracardiac reflection oximeter," Journal of Applied Physiology, vol. 17, no. 3, pp. 552-558, 1962.

[27] Y. Enson, A. G. Jameson, and A. Cournan, "Intracardiac oximetry in congenital heart disease," Circulation, vol. 29, no. 4, pp. 499-507, 1964.

[28] W. J. Gamble, P. G. Hugenholtz, R. G. Monroe, M. Polanyi, and A. S. Nadas, "The use of fiberoptics in clinical cardiac catheterization: I. intracardiac oximetry," Circulation, vol. 31, no. 3, pp. 328-343, 1965.

[29] P. G. Hugenholtz, W. J. Gamble, R. G. Monroe, and M. Polanyi, "The use of fiberoptics in clinical cardiac catheterization: II. in vivo dye-dilution curves," Circulation, vol. 31, no. 3, pp. 344-355, 1965.

[30] P. L. Frommer, J. Ross, D. T. Mason, J. H. Gault, and E. Braunwald, "Clinical applications of an improved, rapidly responding fiberoptic catheter," The American Journal of Cardiology, vol. 15, no. 6, pp. 672-679, 1965.

[31] D. C. Harrison, N. S. Kapany, H. A. Miller, N. Silbertrust, W. L. Henry, and R. P. Drake, "Fiber optics for continuous in vivo monitoring of oxygen saturation," American Heart Journal, vol. 71, no. 6, pp. 766-774, 1966.

[32] B. McCarthy, W. B. Hood, and B. Lown, "Fiberoptic monitoring of cardiac output and hepatic dye clearance in dogs," Journal of Applied Physiology, vol. 23, no. 5, pp. 641-645, 1967.

[33] G. A. Mook, P. Osypka, R. E. Sturm, and E. H. Wood, "Fiber optic reflection photometry on blood," Cardiovascular Research, vol. 2, no. 2, pp. 199-209, 1968.

[34] P. G. Hugenholtz, H. R. Wagner, and R. C. Ellison, "Application of fiberoptic dye-dilution technic to the assessment of myocardial function. I. description of technic and results in 100 patients with congenital or acquired heart disease," The American Journal of Cardiology, vol. 24, no. 1, pp. 79-94, 1969.

[35] R. Singh, A. J. Ranieri, H. R. Vest, D. L. Bowers, and J. F. Dammann, "Simultaneous determinations of cardiac output by thermal dilution, fiberoptic and dye-dilution methods," The American Journal of Cardiology, vol. 25, no. 5, pp. 579-587, 1970.

[36] F. Clark, E. Schmidt, and R. DeLaCroix, "Fiber optic blood pressure catheter with frequency response from DC into the audio range," in Proceedings of the Natiotnal Electronics Conference, McCormick Place, Chicago, Illinois, USA, Oct. 25-27, pp. 213-216, 
1965.

[37] A. Lekholm and L. H. Lindström, "Optoelectronic transducer for intravascular measurements of pressure variations," Medical and Biological Engineering and Computing, vol. 7, no. 3, pp. 333-335, 1969.

[38] A. Ramirez, W. B. Hood, M. Polanyi, R. Wagner, N. A. Yankopoulos, and W. H. Abelmann, "Registration of intravascular pressure and sound by a fiberoptic catheter," Journal of Applied Physiology, vol. 26, no. 5, pp. 679-683, 1969.

[39] L. H. Lindström, "Miniaturized pressure transducer intended for intravascular use," IEEE Transactions on Biomedical Engineering, vol. 17, no. 3, pp. 207-219, 1970.

[40] G. E. Burch and W. A. Sodeman, "The estimation of the subcutaneous tissue pressure by a direct method," The Journal of Clinical Investigation, vol. 16, no. 6, pp. 845-850, 1937.

[41]K. R. Kaufman, T. Waveringb, D. Morrowa, J. Davisc, and R. L. Lieberc, "Performance characteristics of a pressure microsensor," Journal of Biomechanics, vol. 36, no.2, pp. 283-287, 2003.

[42] E. K. Franke, "Miniature pressure gauge for the measurement of intravascular blood pressure," US Patent 3215135, Nov. 12, 1965.

[43] W. E. Frank, "Detection and measurement device having a small flexible fiber transmission line," US Patent 3273447, Sept. 20, 1966.

[44] E. G. Valliere, "Optical catheter means," US Patent 3267932, Aug. 23, 1966.

[45] S. Morikawa, "Fiberoptic catheter-tip pressure transducer," Japanese Journal of Medical Electronics and Biological Engineering, vol. 10, no. 1, pp. 36-39, 1972.

[46] K. Kobayashi, H. Okuyama, T. Kato, and T. Yasuda, "Fiberoptic catheter-tip micromanometer," Japanese Journal of Medical Electronics and Biological Engineering, vol. 15, no. 7, pp. 465-472, 1977.

[47] J. B. Taylor, B. Lown, and M. Polanyi, "In vivo monitoring with a fiber optic catheter," The Journal of the American Medical Association (JAMA), vol. 221, no. 7, pp. 667-673, 1972.

[48] H. Matsumoto, M. Saegusa, K. Saito, and K. Mizoi, "The development of a fiber optic catheter tip pressure transducer," Journal of Medical Engineering and Technology, vol. 2, no. 5, pp. 239-242, 1978.

[49] L. Tenerz, L. Smith, and B. Hok, "A fiberoptic silicon pressure microsensor for measurements in coronary arteries," in IEEE International Conference Solid-State Sensor Actuator, San Francisco,
California, USA, Jun. 24-27, pp. 1021-1023, 1991.

[50]O. Tohyama, M. Kohashi, K. Yamamoto, and H. Itoh, "A fiber-optic silicon pressure sensor for ultra-thin catheters," Sensors and Actuators A: Physical, vol. 54, no. 1-3, pp. 622-625, 1996.

[51] C. Strandman, L. Smith, L. Tenerz, and B. Hök, “A production process of silicon sensor elements for a fiber-optic pressure sensor," Sensors and Actuators A: Physical, vol. 63, no. 1, pp. 69-74, 1997.

[52] O. Tohyama, M. Kohashi, M. Fukui, and H. Itoh, "A fiber-optic pressure microsensor for biomedical applications," Sensors and Actuators A: Physical, vol. 66, no. 1-3, pp. 150-154, 1998.

[53] E. Kalvesten, L. Smith, L. Tenerz, and G. Stemme, "The first surface micromachined pressure sensor for cardiovascular pressure measurements," in Proceedings - The Eleventh Annual International Workshop on Micro Electro Mechanical Systems, 1998, MEMS 98, Heidelberg, Germany, Jan. 25-29, pp. 574-579, 1998.

[54] F. Epstein, A. Wald, and G. M. Hochwald, "Intracranial pressure during compressive head wrapping in treatment of neonatal hydrocephalus," Pediatrics, vol. 54, no. 6, pp. 786-790, 1974.

[55] A. Wald, K. Post, J. Ransohoff, W. Hass, and F. Epstein, "A new technique for monitoring epidural intracranial pressure," Medical Instrumentation, vol. 11, no. 6, pp. 352-354, 1977.

[56] A. Wald, "Monitoring intracranial pressure," Journal of Clinical Engineering, vol. 3, no. 4, pp. 383-388, 1978.

[57] D. Vidyasagar and T. N. K. Raju, "A simple noninvasive technique of measuring intracranial pressure in the newborn," Pediatrics, vol. 59, no. 6, pp. 957-961, 1977.

[58] D. Vidyasagar, T. N. Raju, and J. Chiang , “Clinical significance of monitoring anterior fontanel pressure in sick neonates and infants," Pediatrics, vol. 62, no. 6, pp. 996-999, 1978.

[59] P. R. Holbrook, "1132 noninvasive measurement of intracranial pressure: evaluation of a technique," Pediatric Research, vol. 12, pp. 552, 1978.

[60] N. J. Coroneos, D. G. McDowall, R. M. Gibson, V. W. Pickerodt, and N. P. Keaney, "Measurement of extradural pressure and its relationship to other intracranial pressures: an experimental and clinical study," Journal of Neurology, Neurosurgery \& Psychiatry, vol. 36, no. 4, pp. 514-522, 1973.

[61] INTEGRA. (2010, 10 Dec). Directions for use: OLM Intracranial pressure monitoring kit Model 110-4B. Available: http://integralife.com/products/PDFs/ Camino/110-4B.pdf. 
[62] D. B. Keck, "Optoelectronics in Japan and the United States," Japanese Technology Evaluation Center (JTEC), Baltimore, Maryland, USA, February, 1996.

[63] A. G. Crenshaw, J. R. Styf, S. J. Mubarak, and A. R. Hargens, "A new transducer-tipped fiber optic catheter for measuring intramuscular pressures," Journal of Orthopaedic Research, vol. 8, no. 3, pp. 464-468, 1990.

[64] A. G. Crenshaw, J. R. Styf, and A. R. Hargens, "Intramuscular pressures during exercise: an evaluation of a fiber optic transducer-tipped catheter system," European Journal of Applied Physiology, vol. 65, no. 2, pp. 178-182, 1992.

[65]M. Nakhostine, J. R. Styf, S. V. Leuven, A. R Hargens, and D. H. Gershuni, "Intramuscular pressure varies with depth: the tibialis anterior muscle studied in 12 volunteers," Acta Orthopaedica, vol. 64, no. 3, pp. 377-381, 1993.

[66] P. Peters, S. R. Baker, P. W. Leopold, N. A. Taub, and K. G. Burnand, "Compartment syndrome following prolonged pelvic surgery," British Journal of Surgery, vol. 81, no. 8, pp. 1128-1131, 1994.

[67] K. R. Kaufman and D. H. Sutherland, "Dynamic intramuscular pressure measurement during gait," Operative Techniques in Sports Medicine, vol. 3, no. 4, pp. 250-255, 1995.

[68] R. A. Pedowitz, D. H. Gershuni, A. G. Crenshaw, S. L. Petras, L. A. Danzig, and A. R. Hargens, "Intraarticular pressure during continuous passive motion of the human knee," Journal of Orthopaedic Research, vol. 7, no. 4, pp. 530-537, 1989.

[69] W. Inokuchi, O. B. Sanderhoff, J. O. Søjbjerg, and O. Sneppen, "The relation between the position of the glenohumeral joint and the intraarticular pressure: an experimental study," Journal of Shoulder and Elbow Surgery, vol. 6, no. 2, pp. 144-149, 1997.

[70]C. M. Sommerich, W. S. Marras, and M. Parnianpour, "A method for developing biomechanical profiles of hand-intensive tasks," Clinical Biomechanics, vol. 13, no. 4-5, pp. 261-271, 1998.

[71] K. Iba, T. Wada, M. Aoki, H. Tsuji, T. Oda, and T. Yamashita, "Intraoperative measurement of pressure adjacent to the ulnar nerve in patients with cubital tunnel syndrome," Journal of Hand Surgery-American, vol. 31, no. 4, pp. 553-558, 2006.

[72] K. Iba, T. Wada, M. Aoki, H. Tsuji, T. Oda, Y. Ozasa, et al., "The relationship between the pressure adjacent to the ulnar nerve and the disease causing cubital tunnel syndrome," Journal of Shoulder and Elbow Surgery, vol. 17, no. 4, pp. 585-588, 2008.
[73] R. K. Narayan, R. S. Bray, C. S. Robertson, L. Gokaslan, and R. G. Grossman, "Experience with a new fiberoptic device for intracranial pressure monitoring," presented at the 55th Annual Meeting American Association Neurological Surgeons, Dallas, Texas, May 3-7, 1987.

[74] J. S. Crutchfield, R. K. Narayan, C. S. Robertson, and L. H. Michael, "Evaluation of a fiberoptic intracranial pressure monitor," Journal of Neurosurgery, vol. 72, no. 3, pp. 482-487, 1990.

[75] G. Gambardella, D. d'Avella, and F. Tomasello, "Monitoring of brain tissue pressure with a fiberoptic device," Neurosurgery, vol. 31, no. 3, pp. 918-922, 1992.

[76] J. S. Yablon, H. J. Lantner, T. M. McCormack, S. Nair, E. Barker, and P. Black, "Clinical experience with a fiberoptic intracranial pressure monitor," Journal of Clinical Monitoring and Computing, vol. 9, no. 3, pp. 171-175, 1993.

[77] M. Czosnyka, Z. Czosnyka, and J. Pickard, "Laboratory testing of three intracranial pressure microtransducers: technical report," Neurosurgery, vol. 38, no. 1, pp. 219-224, 1996.

[78]P. H. Raboel, J. Bartek, M. Andresen, B. M. Bellander, and B. Romner, "Intracranial pressure monitoring: invasive versus non-invasive methods: a review," Critical Care Research and Practice, vol. 2012, Article ID 950393 (14 pages), 2012.

[79] P. Hollingsworth-Fridlund, H. Vos, and E. K. Daily, "Use of fiber-optic pressure transducer for intracranial pressure measurements: a preliminary report," Heart and Lung, vol. 17, no. 2, pp. 111-120, 1988.

[80] N. Bruder, P. N'Zoghe, N. Graziani, D. Pelissier, F. Grisoli, and G. François, "A comparison of extradural and intraparenchymatous intracranial pressures in head injured patients," Intensive Care Medicine, vol. 21, no. 10, pp. 850-852, 1995.

[81] E. Münch, R. Weigel, P. Schmiedek, and L. Schürer, "The CAMINO intracranial pressure device in clinical practice: reliability, handling characteristics and complications," Acta Neurochirurgica, vol. 140, no. 11, pp. 1113-1120, 1998.

[82]R. Martinez-Manas, D. Santamarta, J. M. de Campos, and E. Ferrer, "Camino ${ }^{\circledR}$ intracranial pressure monitor: prospective study of accuracy and complications," Journal of Neurology, Neurosurgery \& Psychiatry, vol. 69, no. 1, pp. 82-86, 2000.

[83] I. Piper, A. Barnes, D. Smith, and L. Dunn, "The Camino intracranial pressure sensor: is it optimal technology? an internal audit with a review of current intracranial pressure monitoring 
technologies," Neurosurgery, vol. 49, no. 5, pp. 1158-1165, 2001.

[84] R. Stendel, J. Heidenreich, A. Schilling, R. Akhavan-Sigari, R. Kurth, T. Picht, et al., "Clinical evaluation of a new intracranial pressure monitoring device," Acta Neurochirurgica, vol. 145, no. 3, pp. 185-193, 2003.

[85] M. Gelabert-Gonzalez, V. Ginesta-Galan, R. Sernamito-García, A. G. Allut, J. Bandin-Diéguez, and R. M. Rumbo, "The Camino intracranial pressure device in clinical practice. assessment in a 1000 cases," Acta Neurochirurgica, vol. 148, no. 4, pp. 435-441, 2006.

[86] M. Smith, "Monitoring intracranial pressure in traumatic brain injury," Anesthesia and Analgesia, vol. 106, no. 1, pp. 240-248, 2008.

[87] P. K. Eide, "Comparison of simultaneous continuous intracranial pressure (ICP) signals from ICP sensors placed within the brain parenchyma and the epidural space," Medical Engineering and Physics, vol. 30, no. 1, pp. 34-40, 2008.

[88] A. Bekar, S. Doğan, F. Abas, B. Caner, G. Korfali, H. Kocaeli, et al., "Risk factors and complications of intracranial pressure monitoring with a fiberoptic device," Journal of Clinical Neuroscience, vol. 16, no. 2, pp. 236-240, 2009.

[89] R. A. Wolthuis, G. L. Mitchell, E. Saaski, J. C. Hartl, and M. A. Afromowitz, "Development of medical pressure and temperature sensors employing optical spectrum modulation," IEEE Transactions on Biomedical Engineering, vol. 38, no. 10, pp. 974-981, 1991.

[90] K. Totsu, Y. Haga, and M. Esashi, "Ultra-miniature fiber-optic pressure sensor using white light interferometry," Journal of Micromechanics and Microengineering, vol. 15, no. 1, pp. 71-75, 2005.

[91] P. Polygerinos, T. Schaeffter, L. Seneviratne, and K. Althoefer, "A fiber-optic catheter-tip force sensor with MRI compatibility: a feasibility study," in Annual International Conference of the IEEE Engineering in Medicine and Biology Society (EMBC 2009), Minneapolis, Minnesota, Sept. 3-6, pp. 1501-1504, 2009.

[92] P. Polygerinos, T. Schaeffter, L. Seneviratne, R. Razavi, and K. Althoefer, "Novel miniature MRI-compatible fiber-optic force sensor for cardiac catheterization procedures," in IEEE International Conference on Robotics Automation (ICRA), Anchorage, Alaska, USA, May 3-7, pp. 2598-2603, 2010.

[93] J. N. Fields, C. K. Asawa, O. G. Ramer, and M. K. Barnoski, "Fiber optic pressure sensor,"
Journal of the Acoustical Society of America, vol. 67, no. 3, pp. 816-818, 1980.

[94] H. F. Taylor, "Bending effects in optical fibers," Journal of Lightwave Technology, vol. 2, no. 5, pp. 617-628, 1984.

[95] S. Silvestri and E. Schena, "Optical-fiber measurement systems for medical applications," in Optoelectronics: Devices and Applications. P. Predeep, Ed. Rijeka, Croatia: InTech, pp. 205-224, 2011.

[96]H. K. Kopola, O. Mantyla, M. Makiniemi, K. Mahonen, and K. Virtanen, "Instrument for measuring human biting force," in Proc. SPIE, vol. 2331, pp. 149-155, 1995.

[97] P. V. Komi, A. Belli, V. Huttunen, R. Bonnefoy, A. Geyssant, and J. R. Lacour, "Optic fiber as a transducer of tendomuscular forces," European Journal of Applied Physiology and Occupational Physiology, vol. 72, no. 3, pp. 278-280, 1996.

[98] A. N. Arndt, P. V. Komi, G. P. Brüggemann, and J. Lukkariniemi, "Individual muscle contributions to the in vivo Achilles tendon force," Clinical Biomechanics, vol. 13, no. 7, pp. 532-541, 1998.

[99] T. Finni, S. Ikegaw, V. Lepola, and Paavo Komi, "In vivo behavior of vastus lateralis muscle during dynamic performances," European Journal of Sport Science, vol. 1, no. 1, pp. 1-13, 2001.

[100] M. Ishikawa, P. V. Komi, M. J. Grey, V. Lepola, and G. P. Bruggemann, "Muscle-tendon interaction and elastic energy usage in human walking," Journal of Applied Physiology, vol. 99, no. 2, pp. 603-608, 2005.

[101] C. Nicol, P. V. Komi, A. Belli, V. Huttunen, and E. Partio, "Reflex contribution to Achilles tendon forces: in-vivo measurements with the optic fiber technique," presented at ISB XVth Congress, Jiväskylä, Finland, 1995.

[102] T. Finni, P. V. Komi, and J. Lukkariniemi, “Achilles tendon loading during walking: application of a novel optic fiber technique," European Journal of Applied Physiology, vol. 77, no. 3, pp. 289-291, 1998.

[103] T. Finni, P. V. Komi, and V. Lepola, "In vivo human triceps surae and quadriceps femoris muscle function in a squat jump and counter movement jump," European Journal of Applied Physiology, vol. 83, no. 4-5, pp. 416-426, 2000.

[104] A. Erdemir, S. J. Piazza, and N. A. Sharkey, "Influence of loading rate and cable migration on fiberoptic measurement of tendon force," Journal of Biomechanics, vol. 35, no. 6, pp. 857-862, 2002.

[105] G. W. Hall, J. R. Crandall, D. V. Carmines, and 
J. E. Hale, "Rate-independent characteristics of an arthroscopically implantable force probe in the human achilles tendon," Journal of Biomechanics, vol. 32, no. 2, pp. 203-207, 1999.

[106] A. Erdemir, A. J. Hamel, S. J. Piazza, and N. A. Sharkey, "Fiberoptic measurement of tendon forces is influenced by skin movement artifact," Journal of Biomechanics, vol. 36, no. 3, pp. 449-455, 2003.

[107] J. H. Müller, C. Scheffer, and A. Elvin, "In vivo detection of patellar tendon creep using a fiber-optic sensor," International Journal of Medical Engineering and Informatics, vol. 1, no. 2, pp. 155-173, 2008.

[108] B. C. Fleming and B. D. Beynnon, "In vivo measurement of ligament/tendon strains and forces: a review," Annals of Biomedical Engineering, vol. 32, no. 3, pp. 318-328, 2004.

[109] A. T. Augousti and A. Raza, "The development of a fiber-optic respiratory plethysmograph (FORP)," in Sensors VI: Technology, Systems and Applications Proceedings of the sixth conference on Sensors and their Applications, Manchester, UK, Sept. 12-15, pp. 401-406, 1993.

[110] A. T. Augousti, "A theoretical study of the robustness of the isovolume calibration method for a two-compartment model of breathing, based on an analysis of the connected cylinders model," Physics in Medicine and Biology, vol. 42, no. 2, pp. 283-291, 1997.

[111] A. T. Augousti, A. Raza, and M. Graves, "Design and characterization of a fiber optic respiratory plethysmograph (FORP)," in Biomedical Sensing, Imaging, and Tracking Technologies I, San Jose, California, USA, Jan. 27, pp. 250-257, 1996.

[112] A. T. Augousti, F. X. Maletras, and J. Mason, "Improved fiber optic respiratory monitoring using a figure-of-eight coil," Physiological Measurement, vol. 26, no. 5, pp. 585-590, 2005.

[113] C. Davis, A. Mazzolini, and D. Murphy, "A new fiber optic sensor for respiratory monitoring," Australasian Physical and Engineering Sciences in Medicine, vol. 20, no. 4, pp. 214-219, 1997.

[114] C. Davis, A. Mazzolini, J. Mills, and P. Dargaville, "A new sensor for monitoring chest wall motion during high-frequency oscillatory ventilation," Medical Engineering and Physics, vol. 21, no. 9, pp. 619-623, 1999.

[115] A. Babchenko, A. Babchenko, B. Khanokh, Y. Shomer, and M. Nitzan, "Fiber optic sensor for the measurement of respiratory chest circumference changes," Journal of Biomedical Optics, vol. 4, no.
2, pp. 224-229, 1999.

[116] D. J. Sturman and D. Zeltzer, "A survey of glove-based input," IEEE Computer Graphics and Applications, vol. 14, no. 1, pp. 30-39, 1994.

[117] L. Simone and D. Kamper, "Design considerations for a wearable monitor to measure finger posture," Journal of NeuroEngineering and Rehabilitation, vol. 2, no. 1, pp. 5, 2005.

[118] O. Portillo-Rodriguez, C. A. Avizzano, E. Sotgiu, S. Pabon, A. Frisoli, J. Ortiz, et al., "A wireless bluetooth dataglove based on a novel goniometric sensors," in the 16th IEEE International Symposium on Robot and Human interactive Communication, 2007, RO-MAN 2007, Jeju, Korea, Aug. 26-29, pp. 1185-1190, 2007.

[119] L. Dipietro, A. M. Sabatini, and P. Dario, "A survey of glove-based systems and their applications," IEEE Transactions on Systems, Man, and Cybernetics, Part C: Applications and Reviews, vol. 38, no. 4, pp. 461-482, 2008.

[120] T. G. Zimmerman, J. Lanier, C. Blanchard, S. Bryson, and Y. Harvill, "A hand gesture interface device," SIGCHI Bulletin, vol. 18, no. 4, pp. 189-192, 1986.

[121] M. C. Zimmerman, "Optical flex sensor," US Patent 4542291, Sept. 17, 1985.

[122] S. Wise and G. William, "Evaluation of a fiber optic glove for semi-automated goniometric measurements," Journal of Rehabilitation Research and Development, vol. 27, no. 4, pp. 411-424, 1990.

[123] H. Grant and L. Chuen-Ki, "Simulation modeling with artificial reality technology (SMART): an integration of virtual reality and simulation modeling," in Simulation Conference Proceedings, Washington, D.C., Dec. 13-16, vol. 1, pp. 437-441, 1998.

[124] M. Huber, B. Rabin, C. Docan, G. C. Burdea, M. AbdelBaky, and M. R. Golomb, "Feasibility of modified remotely monitored in-home gaming technology for improving hand function in adolescents with cerebral palsy," IEEE Transactions on Information Technology in Biomedicine, vol. 14, no. 2, pp. 526-534, 2010.

[125] M. R. Golomb, B. C. McDonald, S. J. Warden, J. Yonkman, A. J. Saykin, B. Shirley, et al., "In-home virtual reality videogame telerehabilitation in adolescents with hemiplegic cerebral palsy," Archives of Physical Medicine and Rehabilitation, vol. 91, no. 1, pp. 1-8, 2010.

[126] 5DT. (2011, 1 May). Price list. Available: http://www.5dt.com/pricelist.html. 
[127] OFSETH. (2006, 15 Nov.). Optical fiber sensors embedded into technical textile for healthcare. Available: www.ofseth.org/.

[128] J. De Jonckheere, M. Jeanne, A. Grillet, S. Weber, P. Chaud, R. Logier, et al., "OFSETH: optical fiber embedded into technical textile for healthcare, an efficient way to monitor patient under magnetic resonance imaging," in Conference Proceedings IEEE Engineering in Medicine and Biology Society, Lyon, Aug. 22-26, vol. 2007, pp. 3950-3953, 2007.

[129] A. Grillet, D. Kinet, J. Witt, M. Schukar, K. Krebber, F. Pirotte, et al., "Optical fiber sensors embedded into medical textiles for healthcare monitoring," IEEE Sensors Journal, vol. 8, no. 7, pp. 1215-1222, 2008.

[130] J. De Jonckheere, F. Narbonneau, D. Kinet, J. Zinke, B. Paquet, A. Depre, et al., "Optical fiber sensors embedded into technical textile for a continuous monitoring of patients under Magnetic Resonance Imaging," in Conference Proceedings IEEE Engineering in Medicine and Biology Society, vol. 2008, pp. 5266-5269, 2008.

[131] J. De Jonckheere, F. Narbonneau, D. Kinet, J. Witt, K. Krebber, B. Paquet, et al., "OFSETH: smart medical textile for continuous monitoring of respiratory motions under magnetic resonance imaging," in Conference Proceedings - IEEE Engineering in Medicine and Biology Society, Minneapolis, Sept. 3-6, pp. 1473-1476, 2009.

[132] J. De Jonckheere, M. Jeanne, F. Narbonneau, J. Witt, B. Paquet, D. Kinet, et al., "OFSETH: a breathing motions monitoring system for patients under MRI," in Conference Proceedings - IEEE Engineering in Medicine and Biology Society, Buenos Aires, Aug. 31 - Sept. 4, pp. 1016-1019,
2010.

[133] J. De Jonckheere, F. Narbonneau, D. Kinet, J. Zinke, B. Paquet, A. Depre, et al., "Optical fiber sensors embedded into technical textile for a continuous monitoring of patients under magnetic resonance imaging," in Engineering in Medicine and Biology Society, 2008. EMBS 2008. 30th Annual International Conference of the IEEE, Vancouver, Aug. 20-25, pp. 5266-5269, 2008.

[134] W. C. Wang, W. R. Ledoux, C. Y. Huang, C. S. Huang, G. K. Klute, and P. G.. Reinhall, "Development of a microfabricated optical bend loss sensor for distributive pressure measurement," IEEE Transactions on Biomedical Engineering, vol. 55, no. 2, pp. 614-625, 2008.

[135] W. C. Wang, W. R. Ledoux, B. J. Sangeorzan, P. G.. Reinhall, "A shear and plantar pressure sensor based on fiber-optic bend loss," Journal of Rehabilitation Research and Development, vol. 42, no. 3, pp. 315-25, 2005.

[136] W. C. Wang, C. T. Ho, Y. R. Lian, and W. C. Chuang, "Transducing mechanical force by use of a diffraction grating sensor," Applied Optics, vol. 45, no. 9, pp. 1893-1897, 2006.

[137] W. C. Wang, C. Y. Huang, T. K. Chiang, and P. G. Reinhall, "Optical and mechanical characterization of microfabricated optical bend loss sensor for distributive pressure measurement," in Health Monitoring Structural and Biological Systems 2007, San Diego, California, USA, Mar. 19-22, pp. 65321K-10, 2007.

[138] W. Soetanto, N. T. Nguyen, and W. C. Wang, "Fiber optic plantar pressure/shear sensor," in Proc. SPIE, vol. 7984, pp. 79840Z-1-79840Z-7, 2011. 